\title{
Research on the Governance Reform of Big Science Infrastructures in China: Based on the Perspective of Administrative Subcontract
}

\author{
Zhenyu Huang* \\ School of Public Administration and Humanities, Dalian Maritime University, Dalian 116026, China \\ "Corresponding author. Email: hzyhit@163.com
}

\begin{abstract}
Based on the perspective of administrative subcontracting, this paper builds a framework to analyze the governance changes occurring in China's big science infrastructures (BSIs). The construction goal of BSIs has always been based on basic research, with the formation of a "central ministries-operational organization" administrative subcontracting relationship. Under this relationship, the governance rights were mainly monopolized by the Chinese Academy of Sciences or research universities, the government lacked effective governance authority, and retention of the status quo was the only optional strategy regardless of the assessment result, which was not an effective development model. With the construction of comprehensive national science centre, BSIs have emerged a new construction goal which is supporting industrial development. In the new era with the theme of "innovation-driven development", local governments have begun to embed in the administrative subcontracting relationship, and "changing subcontracting tasks" and "changing subcontractors" have been added as alternative technocratic strategies, rebuilding the governance authority of government and promoting the formation of a sustainable governance model for BSIs.
\end{abstract}

Keywords: Administrative Subcontract, Big Science Infrastructure, Local Government, Governance Authority, Technocratic Strategy

\section{INTRODUTION}

Big science infrastructures (BSIs) originated from the "Manhattan Project" during World War II, and in China, they are also called "major national science and technology infrastructure". China's investment in BSIs has been on the rise since the reform and opening up. In China, BSIs were primarily positioned to support or assist basic scientific research. Related literature has paid close attention to aspects related to BSIs management system, performance evaluation index, financial sources, organizational structure and foreign scientific institutions, etc. [1][2][3]. However, according to our recent investigation, we found that with the construction of the comprehensive national science centre construction since 2016, changes in the governance of China's BSIs have already been underway, while research on related phenomena remains to be carried out.

It is important to study the governance reform of BSIs in China. The huge public financial investment in BSIs is not only a scientific research behaviour, but also a government behaviour. However, whether in practice or academic research, the role of "government" has been absent in the governance of BSIs in China. The absence of government in practice leads to governance problems such as academic misconduct, waste of resources, deviation from objectives and so on. The absence of government in research is not helpful for making appropriate explanation for the government's behaviour of investment and governance of BSIs. Therefore, from the perspective of administrative subcontracting, this paper explains the current practice of Chinese government' embedding in BSIs governance, which may enrich the research on government behaviour in this field.

\section{THEORETICAL PERSPECTIVE AND ANALYTICAL FRAMEWORK}

\subsection{Administrative subcontracting and governance}

The concept of "administrative subcontracting" 
originates from firm theory in economics. This theory distinguishes two main models of firm governance: subcontracting and employment. The former is a market trade relationship between firms, while the latter refers to the administrative-order relationship within a firm [4][5]. Furthermore, this theory addresses the production problem with regard to "the decision of make-or-buy", which concerns the firm boundary, as determined by Coase's transaction costs theory [6][7]. Through the transformation and development of the differences between subcontracting and employment relations in firm theory, Zhou proposed the concept of "administrative subcontracting" [5].

Zhou points out that "administrative subcontracting" is the relationship of subcontracting embedded between superiors and subordinates, which is all under a unified authority. It is systematically different from bureaucracy and a pure outsourcing system in regard to the three dimensions of the "power distribution, economic incentive and control-by-evaluation" [5]. Because of the unique connotation and value of administrative subcontracting in analysing intergovernmental relations, bureaucrat incentives and government governance, scholars have already used this theory and conducted research in related fields. For example, Huang and Zhou applied the administrative subcontracting system to the study of Chinese social organizations and re-examined the relationship between social organizations and the government during transformation [8]. Du took financial and administrative power in administrative subcontracting as the starting point to explain the rise and fall of political power in the Xi Han Dynasty [9]. Meng held that Chinese central and local financial decentralization reflects the logic of the administrative subcontracting system and reflects the reality of financial decentralization in regard to the dimensions of the administrative power distribution, economic incentive, internal evaluation and control [10].

The perspective of administrative subcontracting is widely used in depicting intergovernmental relations and the relationship between government and social organizations. It also systematically explains the characteristics of government governance in China and analyses phenomena in the superior government's process of subcontracting tasks.

\subsection{Three perspective of administrative subcontracting}

The power distribution, economic incentive and control-by-evaluation are three analytical dimensions of the administrative subcontracting. Specifically, for the power distribution dimension, Zhou points out that it has two basic characteristics: First, the employer has formal authority and residual rights of control, and this kind of "power distribution within an administrative organization between the superior and subordinate" is different from the equal contractual relationship of outsourcing. Second, the subcontractor has the right of implementation and decision making, as Zhou points out that the subcontractor owns actual control rights with a certain amount of discretion [5].

Regarding the second dimension, in terms of the economic incentive, the important characteristic of administrative subcontracting is "subcontracting", which is different from the bureaucratic system characterized by administration. In administrative subcontracting, "the subcontractor has the residual claim rights and faces a strong incentive" [8]. From the administrative subcontracting perspective, the relationship between the subcontractor and employer is financial or concerns budgetary appropriations; thus, the subcontractor has residual claim rights, which means that the subcontractor has all other rights after submitting to the superior as required, forming a very strong incentive with regard to personnel arrangements.

Regarding the third dimension, control-byevaluation, the internal control of administrative subcontracting is result oriented and resembles responsibility sharing, which is different from bureaucracy that emphasizes procedure and rules. The task index issued by the superior government is often based on results only, and whether the subcontractor has the ability or conditions to complete or to make progress in executing the task is strictly in line with procedures or principles that do not affect the decision of the superior government. However, this aspect is also a main reason why the subcontracting task is distorted and why execution becomes flexible. Under the administrative subcontracting system, the superior's control-by-evaluation can depend only on the final results because the subcontractor owns the right of discretion and the ability of information control [11].

\subsection{Analysis framework: Administrative subcontracting as technocratic strategy}

In current fields such as sociology, politics and public administration, in addition to being used to explain the governance characteristics or logic of the Chinese government, administrative subcontracting is considered a social technology or administrative technology formed in the context of rationalized social operation or scientific political activities, which means that administrative subcontracting is a kind of technical governance [12][13]. In fact, technical governance is the proper meaning of administrative subcontracting. The theoretical source of administrative subcontracting is enterprise theory, and research on subcontracting or employment based on enterprise theory focuses on the theoretical study of the enterprise organizational boundary decision and emphasizes the significance of subcontracting or employment, such as obtaining specialized services, integrating resources and 
improving innovation capability [14][15]. Therefore, the governance logic and behaviour based on administrative subcontracting must imply a corresponding technocratic strategy.

From the employer perspective, the power distribution is a core dimension that embodies the "administrative" connotation of government governance and distinguishes it from pure subcontracting because the appropriateness of the power distribution will seriously affect the completion effect of subcontracting tasks. First, when the government determines the task subcontractor, it will provide administrative support, for example, in terms of the power distribution and resource allocation when contracting out the task-clearly, the more specialized and difficult the task, the greater the discretion that the subcontractor has. Second, in a situation of information asymmetry, especially where the subcontractor can control upward information disclosure, the government as the task employer can evaluate only the output task results and then make further decisions based on the assessment feedback of the task results. Third, the right of government governance is composed of formal authority and the residual control right, which is the main guarantee allowing the government to "control important decisions, veto, restrain and supervise the decisions and behaviours of subcontractors" [11]. Here, the right of government governance right mainly includes three types of technocratic strategies: (1) retaining the status quo, which means not changing the task or the subcontractor; (2) changing the subcontracting task or adjusting the subcontracting content; and (3) changing the subcontractor and selecting a new subcontractor.

From the subcontractor perspective, discretion, the strong incentive and result-oriented assessment are the characteristics of subcontracting, which are different from bureaucracy, characterized by weak incentives and its programmed nature [5]. The first characteristic involves introducing a subcontracting system within the scope of administrative power so that different governance areas or governance objects can establish different autonomous governance organizations and mechanisms based on the characteristics of tasks [8]. Regarding the second characteristic, subcontracting grants residual claim rights to the subcontractor, and as a result, the subcontractor faces a strong incentive. Although this incentive mechanism combined with discretion can save considerable supervision and management costs for the employer, it also produces the risk of concealment and distortion in the execution progress of the task [11]. Third, with regard to resultoriented assessment, because the subcontractor can control information disclosure, the task execution process is like a "black box", and the employer can assess only the completion of the task by relying on the final output results. At this time, when the task results are concealed and distorted, the employer with governance rights (formal authority and residual control rights) can implement strategy-based interventions.

In short, we construct a technical governance framework based on the perspective of administrative subcontracting, as shown in Figure 1. From this perspective, as a technocratic strategy, the governance right is the basic guarantee for the effective governance of subcontracting tasks. If the employer lacks the governance right, the subcontractor will not be affected regardless of the result of the task.

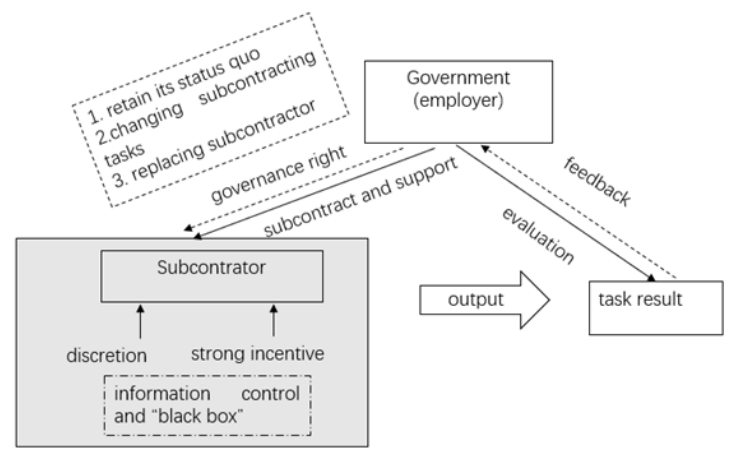

Figure 1 Technocracy Framework Based on The Perspective of Administrative Subcontracting.

\section{BEFORE REFORM: THE "CENTRAL MINISTRIES-OPERATIONAL ORGANIZATION" ADMINISTRATIVE SUBCONTRACTING RELATIONSHIP}

\subsection{The basic research goal of the BSI}

The 20th century was the golden age of high-energy physics. Many famous big science research organizations were founded in this period, such as the national laboratory system of the United States, the Helmholtz Association of German Research Centres, the Grenoble Science City of France, the Harwell Campus of the United Kingdom, the European Organization for Nuclear Research and the Japan Atomic Energy Research Institute, etc. Various BSIs are used for highenergy physics research, such as large colliders, accelerators, synchrotron radiation light sources, spallation neutron sources, and nuclear reactors, are all typical products of the era. It was in this era that China opened the road to the construction of BSIs. The Beijing Electron Positron Collider, which was the first highenergy accelerator designed and built by China, successfully collided for the first time on October 16, 1988 [16].

In the context of this era, the main goal of China's construction of BSIs was to serve basic research in related scientific fields. Some references indicate that BSIs were built to meet the extreme research conditions of modern scientific research, such as "extremely high energy", "extremely high density", "extremely short time" and "extremely high strength" [17]. For example, 
the Beijing Electron Positron Collider, scientists are arming at $\tau$ and charm physics in high-energy physic research [18]. Hallonsten believes that BSIs are facilities that provide scientists with cutting-edge experimental resources [19]. Additionally, the OECD Global Science Forum regards BSIs as centralized large research infrastructures that support basic scientific research [20]. In 2012, scientists at CERN used the Large Hadron Collider to discover the Higgs boson.

BSIs are still characterized by technological innovation efficiency and by driving industrial development. For example, during the period of the construction of the Beijing Electron Positron Collider, some scholars observed its roles in promoting the development high technology such as magnet manufacturing and in accelerating tube manufacturing and free electron laser [16]. However, the basic scientific research orientation still takes the key position. This orientation has been further highlighted during the period of the 11th Five-Year Plan; that is, Chinese universities have become the leading construction and operation management units of BSIs. As pointed out in the "Research Report on the Construction and Development of Important Scientific and Technological Infrastructure in Colleges and Universities", BSIs are the "the basic conditions for supporting original innovation...At the same time, BSIs were also the basic support system for universities to carry out basic and applied scientific research" [21].

\subsection{Deletion of governance rights: "Retaining the status quo" as the only strategy}

Before the reform, the construction and operational management of BSIs were tasks subcontracted directly by the central ministries to the Chinese Academy of Sciences or research universities. First, the Chinese Academy of Sciences or research universities were the main support units responsible for the construction and operational management of BSIs. Second, there were central policies clearly pointing out that "the National Development and Reform Commission (NDRC) is the leading department of infrastructure construction management, which works with the Ministry of Finance, the Ministry of Science and Technology, the Natural Science Foundation Committee and other departments independently". From the administrative subcontracting perspective, the operational management of BSIs was a task entrusted by the central ministries as the employer to the Chinese Academy of Sciences or research universities as subcontractors of this task. Third, in this process, due to the basic research orientation of BSIs, the investment was large, and the uncertainty was high, which made BSIs less attractive to local Chinese governments, which pay more attention to short-term governance performance [22].
Although there are few public reports on the governance issues of BSIs, relevant scholars and practitioners have already called for and demanded reform of BSI governance. For instance, in a seminar held by the important science and technology infrastructure research group of the Ministry of Education in 2011, scholars from the Huazhong University of Science and Technology, the University of Science and Technology Beijing, the Harbin Institute of Technology, Tsinghua University, and others reached the consensus that the scientific research organization model based on BSIs is different from that of universities because there are two different incentive and assessment systems [21], and operations that rely on universities lead to conflicts.

A survey of "dependent operations" conducted in 2012-2015 found that other academic organizations or scientific institutions within universities will compete for or consume talent and outlays in BSIs [23]. During two sessions in 2016, He Li, a member of the National Committee of the Chinese People's Political Consultative Conference and a former director of the Shanghai Institute of Technical Physics of the Chinese Academy of Sciences, pointed out that the "double employment" system adopted under the "dependent operations" mode had dispersed the research energy of national laboratories (such as the Beijing Electron Positron Collider), and therefore, the system cannot provide an institutional guarantee with regard to national scientific research objectives and scientific research investment [24]. As recently as 2019, at a special symposium on the construction and management of BSIs, some experts pointed out that personnel employment, assessment and evaluation, opening and sharing were still problems that could not be effectively solved under the current "dependent operations" mode.

However, the basic research orientation, the governance "black box" of the "dependent operations" mode, soft budget constraints, the overlong governance span and other factors have led to a lack of governance rights in the subcontracting relationship, and "retaining the status quo" has become the only alternative strategy.

First, under the orientation of basic research, scientific institutions such as the Chinese Academy of Sciences or research universities have become the few optional subcontracting objects for the operation and management of BSIs. In addition, the supporting management units of BSIs are faced with strong incentives brought by residual control rights, such as the long-term large amounts of national scientific research investment, the collection of talent in related fields, and the signature rights of output results. Furthermore, due to the dependence on the management unit as the subcontractor and due to the high degree of scientific research specialization, such units have relatively large discretion and information control rights. Thus, the 
employer can assess only the task results and make governance decisions based on the assessment feedback. Lastly, because of soft budget constraint, regardless of the assessment results, it is difficult for the employer to suspend the continuous operation of BSIs in whose construction an enormous amount of funding has been invested. At the same time, under the conditions of the overlong governance span and limited optional subcontracting objects, the employer cannot choose participation as a conventional means of governance; it can only choose "retaining the status quo". At this time, assessment and feedback are all out of order.

As shown in figure 2, it can be seen from the above that, on the one hand, there is a call for a chance in governance in academia and practical circles. On the other hand, there is a lack of effective governance rights and technocratic strategies in the whole process of administrative subcontracting.

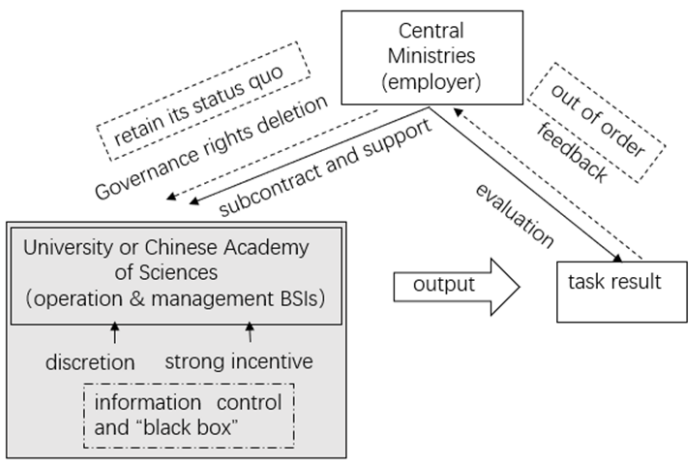

Figure 2 Governance Rights Deletion in Administrative Subcontracting Progress

\section{IN THE REFORM: THE LOCAL GOVERNMENT EMBEDS IN THE ADMINISTRATIVE SUBCONTRACTING RELATIONSHIP}

\subsection{The dual orientation of BSIs: Basic research and industrial development}

With the gradual scaling of BSI construction and development, the Chinese government has successively issued a series of policies and documents, such as "The 13th Five-Year Plan for the Economic and Social Development of The People's Republic of China", "The 13th Five-Year Plan on Technology and Innovation", "The 13th Five-Year Plan on the Construction of Major National Science and Technology Infrastructure" and "The Outline of the National Innovation-Driven Development Strategy". These policies and documents propose building a comprehensive national science centre in areas where BSIs cluster and forming an important birthplace of science and technology with national and even global influence. Beijing, Shanghai and Hefei have been approved for the construction of comprehensive national science centres during the period of the 13th Five-Year Plan. In 2019, the introduction of the "Outline Development Plan for the Guangdong-Hong Kong-Macao Greater Bay Area" and "The Central Committee of the Communist Party of China Guideline for Supporting Shenzhen in Building a Demonstration Pilot Zone for Socialism with Chinese Characteristics" indicated that Shenzhen will be the main location for building a comprehensive national science centre, which will play a key role in the construction of the international science and technology innovation centre of the Guangdong-Hong Kong-Macao Greater Bay Area.

These policies and documents also form the dual orientation of BSIs: basic research and industrial development. For example, from a definitional perspective, as mentioned in the "National Medium- and Long-Term Plan for Major National Science and Technology Infrastructure (2012-2030)" (GF [2013] No.8), "BSIs are a large-scale complex scientific research system that provides extreme research means for exploring the unknown world, discovering natural laws and realizing technological change". Furthermore, the plan proposes that "China's advanced deployment of a number of BSIs in several important areas is conducive to better promoting progress in industrial technology, solving bottleneck scientific problems in economic and social development, and having great significance in accelerating strategic new industries, realizing the transformation of the economic development mode and supporting economic and social development". In terms of the selection of BSIs, the 9 infrastructures in Shenzhen basically coincide with the seven strategic emerging industries in Shenzhen [25]. In other words, in addition to supporting and assisting basic research, BSIs also aim to achieve technological change, promote industrial technology and support economic and social development.

Academic research on the relationship between BSIs and industrial development is increasing. For example, some studies have pointed out that in the process of construction and operation, BSIs can cluster resources that are conducive to economic innovation and growth, form innovation highlands, output high-end technology and drive the development of high-end industries and their technology [26][27]. Furthermore, some studies have argued that building a comprehensive national science centre on the basis of BSI clusters has advantages such as breaking system restrictions and promoting the development of high-tech industries [28][29]. In addition, some studies have analysed theories and countermeasures based on the innovation ecosystem of BSIs [30]. This research shows that practical and academic circles have reached a certain degree of consensus on the dual orientation of BSIs: basic research and industrial development. 


\subsection{The rebuilding of governance rights: The transformation of local government behaviour and exploring the sustainable governance model}

With the construction of socialism with Chinese characteristics entering a new era, innovation has become the source of power for leading economic and social development and building a modernized economic system, which is a new challenge for local governments in the new era. Under the restriction imposed by the requirement to improve the quality and efficiency of economic development and the high information cost of innovation, the subsequent benefits of innovation often cannot be estimated accurately, and it is also difficult to use subsequent benefits such as GDP to perform an evaluation. Therefore, local governments have increasingly turned to prior acts, such as enhancing the strength with which the introduction of talent, innovation, and entrepreneurship are supported. The proposal of the comprehensive national science centre and the international science and technology innovation centre of the Guangdong-Hong Kong-Macao Greater Bay Area provides local governments with a choice of behaviour, which shows the highest degree of advance political achievement: the construction of BSIs. The orientation of industrial development of BSIs is consistent with a statement in "Several Opinions of the State Council on Comprehensively Strengthening Basic Research" (GF [2018] No. 4): "encouraging and guiding local and social forces to invest in the construction of major scientific and technological infrastructure". This policy document provides action incentives and legitimacy for local governments to participate in the construction of BSIs. Under the guidance of the orientation of the objective of new construction and the support of the central government, local governments are embedded in the "central ministries-dependent unit" administrative subcontracting relationship. On the one hand, the behavioural choices of local governments can be observed from recent news reports and government work reports: In addition to the approved cities, Guangzhou, Foshan, Dongguan, Chengdu, Xi'an, Jilin, Dalian, Jinan, Wuhan and other cities have expressed their support for the construction of BSIs and even for the comprehensive national science center. For example, Shenzhen, being at the vanguard of the reform and opening up, started implementing the "top 10 action plans" as early as 2017 and invested in the construction of the BSI cluster in the core area of the Guangming Science City with local financing.

On the other hand, as a result of the embeddedness of local governments, the technocratic strategy options are no longer limited to "retaining the status quo", and governance rights are reconstructed in the administrative subcontracting relationship, initiating the governance reform of China's BSIs. In practice, the embedding methods of local governments have their own characteristics. For example, Beijing and Hefei have established the Huairou Science City Management Committee and the Binhu Science City Management Committee, respectively, and Shanghai has established the Office of Promoting the Construction of the Science and Technology Innovation Centre. Regarding Shenzhen, overall governance will be carried out by the Shenzhen State High-tech Industrial Innovation Centre, which is directly under the Shenzhen Development and Reform Commission. Based on our investigation, we take Shanghai as an example for purposes of further explanation; the governance mode is shown in Figure 3.

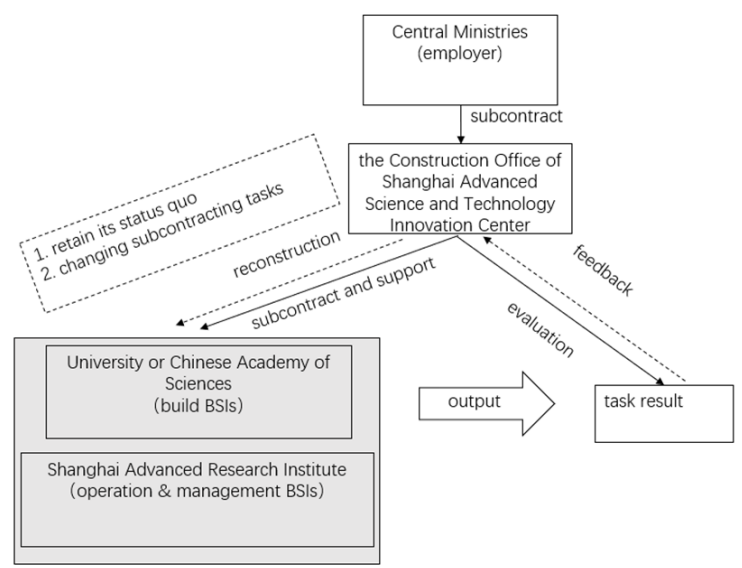

Figure 3 Governance mode of Shanhai

On September 29, 2018, the Construction Office of the Shanghai Advanced Science and Technology Innovation Centre (hereinafter referred to as the "Science and Technology Innovation Office") was officially opened. According to reports, the establishment of the Science and Technology Innovation Office combines the Zhangjiang Science Center, Dazhangjiang Management Committee, Xiaozhangjiang Management Committee and Zhangjiang Free Trade Bureau with the aim of better coordinating the construction, management and service of the Zhangjiang Science City.

Interviewing the person in charge of establishing the Science and Technology Innovation Office and Zhangjiang Laboratory, we found that the central ministries and commissions no longer directly subcontract the construction and operational management tasks of BSIs to a university or to a research institute of the Chinese Academy of Sciences. Instead, first, they subcontract to the Science and Technology Innovation Office and then subcontract through the Science and Technology Innovation Office. At this time, in addition to "retaining the status quo", there is another choice in the subcontracting process: the "changing the subcontracting task" strategy. As the person in charge of Zhangjiang Laboratory said in the interview: 
"In the past, many instructions were used by themselves after they were built. But now, we have split them. That is, if you build the instruction, you should not be a user. If you are a user, you do not have to build the instruction. We just need to be more open. So, at present, there is an important indicator in assessment regarding how many users are using it, not just how many people are using it in your own unit. In terms of knowledge protection, if you are the manager or the main user of the instruction, then other research institutions will not be willing to come to yours because they will be worried that you will get its information. So, the building and the using must be separated".

In other words, it used to be the case that "who led the construction was who was responsible for operational management", but one of the consequences was that, on the one hand, the BSIs were often "occupied for a long time" by the leading construction units, which made it difficult to achieve effective opening and sharing; on the other hand, users were worried about the unethical academic behaviour of the operational unit. Under the technical governance strategy of "changing the subcontracting tasks", Shanghai has adopted the method of "separating building and use", which means that the task of BSI construction is subcontracted to a university or an institute of the Chinese Academy of Sciences and that the operation and management task after completion is subcontracted to the Shanghai Advanced Research Institute, which is currently the construction unit of Zhangjiang Laboratory.

In addition, in the course of the investigation, we also observe that Shenzhen, as the first city to invest in the construction of BSIs through local financing, is exploring a governance mode in which the subcontracting object can be changed according to the needs of the assessment results. The person in charge of the Shenzhen Development and Reform Commission has clearly proposed that whether a BSI is conducive to industrial development is an important indicator in assessing the operation and management organization of BSIs. Therefore, if the assessment is not satisfactory, the organization can be required to take responsibility or can even be replaced.

\section{CONCLUSION}

Based on the perspective of administrative subcontracting, it is revealed that in the new era with the theme of "innovation-driven development", the transformation in the behaviour of local governments and the administrative subcontracting relationship embedded in the construction and operation management of BSIs are currently the trends of BSI governance reform. Compared with the "central ministries-dependent unit" administrative subcontracting relationship, the embeddedness of local government can not only shorten the governance span but also promote the sustainable development of local governments. The governance model being explored shows that different local governments can build different governance systems according to the actual situation, promote the reconstruction of governance rights, and boost technology in the process of administrative subcontracting, which is a technocratic strategic choice, not just "retaining the status quo".

The BSI is the symbol of the era of big science. The human, material and financial resources invested in the construction and operation of BSIs far outpace those of the small science characterized by "free research and truth seeking". As a symbol of the era, BSIs involve a completely different mode of scientific research cooperation compared to that in the era of small science, and the proposal of BSI clusters and a comprehensive national science centre are the concentrated embodiment of this mode of scientific research cooperation. In this process, analysing the governance function and the technocratic strategies of governments, especially local governments, from the administrative subcontracting perspective will help to improve the BSI governance system.

However, the reconstruction of government governance rights does not mean comprehensive intervention and control. Otherwise, the result will be a shift to the opposite extreme, which will not only lose the incentive mechanism of subcontracting, but also contradict the reform of national governance, which is currently exploring a new whole national system in the field of major scientific and technological innovation. Therefore, in the following research, with local governments embedded in the administrative subcontracting relationship for the tasks of BSI construction and operational management, how to determine the governance boundary between the employer and the subcontractor has become an urgent theoretical and practical problem to be solved in current academic and practical circles.

\section{AUTHORS' CONTRIBUTIONS}

All authors have read and approved the final manuscript.

\section{ACKNOWLEDGMENTS}

This research was supported by the National Natural Science Foundation of China (Grant no. 71804203).

\section{REFERENCES}

[1] Wang P \& Zhang S. The statue, character and enlightenment of Argonne National Laboratory's management pattern. Bulletin of National Natural Science Foundation of China, 2011, (3), 173-177. 
[2] He J \& Zheng $Y$ Z. Revelations from the Management on National Labs of U.S. Department of Energy to National Labs Operated by Chinese Universities. Science and Technology Management Research, 2012, (3), 68-72.

[3] Wang H B \& Bai H R. Enlightenment of German mechanism of opening and sharing large-scale scientific facilities. Bulletin of National Natural Science Foundation of China, 2019, (3), 208-312.

[4] Zhou L A. Local government in transition: Officials' incentive and Governance. Shanghai, Shanghai People's publishing house. 2008.

[5] Zhou L A. Administrative subcontract. Chinese Journal of Sociology, 2014, (6), 1-38.

[6] Coase R H. The Nature of the Firm. Economica, 1937, (16), 386-405.

[7] Grossman S J \& Hart O D. The Costs and Benefits of Ownership: A Theory of Vertical and Lateral Integration. Journal of Political Economy, 1986, (4), 691-719.

[8] Huang X C \& Zhou L A. Transition in governmental governance mechanisms and development of social organizations. Social Science in China, 2017, (11), 118-138.

[9] Du C L. Decentralization, governance efficiency and the rise and fall of Western Han regime: On the theory of administrative contract system. Exploration and Free Views, 2017, (10), 149-154.

[10] Meng F. The logic of financial decentralization between central and local government: Administrative subcontract model and its effect. Shanghai Journal of Economics, 2017, (12), 85-97.

[11] Zhou L A. Organizational boundary of administrative subcontracting: An analysis of "the separation of officials and local staff " and stratified mobility. Chinese Journal of Sociology, 2016, (1), 34-64.

[12] Liu Y M. The logic of technocracy. Journal of Renmin University of China, 2016, (6), 118-127.

[13] Huang X C \& Ji X. Limits to Micromanagement and logic of the reform. Journal of Social Science, 2016, (11), 72-79.

[14] Alcacer J \& Oxley J. Learning by supplying. Strategic Management Journal, 2014, (2), 204-223.

[15] Wang Y G et al. Research on the measurement, promotion and performance impact of innovation capability in service outsourcing : Analysis based on the perspective of knowledge transfer between contracting parties and contracting parties. Management World, 2015, (6), 85-98.
[16] Du C et al. Research on the National Large-scale Scientific Facility. Beijing: Beijing University of Technology Press. 2011.

[17] Huang $M \quad \& \quad$ Tang $H \quad Z$. Improvement of management of large scientific facilities in China. Bulletin of Chinese Academy of Sciences, 2006, (3), 213-217.

[18] Wang P \& Zhang S. 2011. The statue, character and enlightenment of Argonne National Laboratory's management pattern. Bulletin of National Natural Science Foundation of China, (3), 173-177.

[19] Hallonsten O. How expensive is Big Science? Consequences of using simple publication counts in performance assessment of large scientific facilities. Scientometrics, 2014, (2), 483-496.

[20] OECD Global Science Forum. 2008. Large Reserch Infrastructures. (2008-06-10)[2019-01-02]. http://120.52.51.19/www.oecd.org/sti/scitech/47057832.pdf.

[21] Huang Z Y \& Ding Y L. Research on Governance Structure and Strategy of Big Science Engineering Organization. Harbin: Harbin Institute of Technology Press. 2016.

[22] Huang X C \& Ji X. Limits to Micromanagement and logic of the reform. Journal of Social Science, 2016, (11), 72-79.

[23] Ding Y L \& Huang Z Y. The system of absorb resources: Separation and reconstruction of the relationship between university and national laboratories. Journal of Public Management, 2015, (3), 105-116.

[24] People. 2016. He: Building the National Laboratory optimization and innovation system. http://scitech.people.com.cn/n1/2016/0310/c100728187624.html.

[25] Nan Fang Daily. How to settle down the large scientific installation group in Shenzhen? 9 major infrastructure projects have been planned. http://news.sznews.com/node_301974.htm. 2019.

[26] Li B \& Li S Q. The investigation report on the economic and social benefits of Heavy Ion Research Facility in Lanzhou. Journal of Engineering Studies, 2015 (1), 3-15.

[27] Zhang L L, Zhao D Z \& Zhang Q L. Research on the industrialization mode based on large-scale scientific facilities. Science \& Technology Progress and Policy, 2017, (19). 53-59.

[28] Chen T \& Feng F. Cluster effect of large-scale scientific facilities and management enlightenment. 
Journal of Northwestern Polytechnical University (Social Sciences), 2015(1), 61-66.

[29] Liang Y F, Pan S T, Lin X et al. Collaborative innovation and industry-driven effect of large-scale scientific facilities cluster: Taking Guangdong large-scale scientific facilities center as an example. Science and Technology Management Research, 2018, (3), 5-10.

[30] Huang Z Y. Building innovative ecosystem based on large scientific infrastructure: Rainforest model and evolutionary transaction cost. Science \& Technology Progress and Policy, 2019, (19), 9-16. 